\title{
Why Do We Need to Know What the Public Thinks about Nanotechnology?
}

\author{
Craig Cormick
}

Received: 26 March 2009 / Accepted: 19 July 2009 /Published online: 28 July 2009

(C) The Author(s) 2009. This article is published with open access at Springerlink.com

\begin{abstract}
Public debate on nanotechnology is a large topic within governments, research agencies, industry and non-government organisations. But depending who you talk to the perception of what the public thinks about nanotechnology can be very varied. To define coherent policy and to invest in research and development that aligns with public preferences, needs more than just perceptions of public perceptions. Public attitude studies are vital in understanding what the public really think, but they need to go further than simplistic polling and should examine factors such as changes over time, drivers of attitude change, different attitudes to different applications and be supported by qualitative data. This paper summarises the findings of a three year tracking study of public attitudes towards nanotechnology, highlighting both concerns and aspirations for nanotechnology and discusses the impacts of that data on public engagement programs.
\end{abstract}

Keywords Public attitudes $\cdot$ Public debate $\cdot$ Risks . Benefits

\section{Introduction}

Nanotechnology was incorporated in an estimated US $\$ 82$ billion worth of manufactured goods in 2008, according to Currall [1] ${ }^{1}$ and appeared in over 800 consumer products on the market. ${ }^{2}$ Pre-Global Financial Crisis estimates were that nanotechnology would be in US\$2.6 trillion worth of goods by $2014 .^{3}$

Yet despite this rapid uptake and the undoubted major impacts that nanotechnology is going to have on our lives, the general public appear to know very little about it. The risk of course, is obvious, that the public may react to the rapid proliferation of nanotechnology the way they reacted to GM crops, and a large consumer backlash against nanoproducts would be understandable if product developers were not developing products that aligned with public needs or values.

However, as has been pointed out by Kahan, Slovic, Braman, Gastil and Choen, "Not much more is known about public perception of the risks of nanotechnology than is known about nanotechnology risks themselves."4

The answer in many countries is to try and match rapid product development with increased public

\footnotetext{
${ }^{1}$ Nanotechnology: A Global Strategic Business Report [8].

${ }^{2}$ Project on Emerging Nanotechnologies Consumer Product Inventory [12].

${ }^{3}$ Rejeski et al. [14].

${ }^{4}$ Kahan et al. [6].
}

C. Cormick $(\bowtie)$

Australian Office of Nanotechnology,

Canberra, Australia

e-mail: Craig.cormick@innovation.gov.au 
understanding and awareness of nanotechnology. But this might be only half the answer, as improved understanding of what the public actually know and think about nanotechnology should also inform public policy development and product development.

There are, of course, many advocacy groups who are willing to state what they believe the public feel about nanotechnology, whether that be highly supportive of or highly concerned about the technology. For example, Friends of the Earth's Out of the Laboratory and on to our Plates, publication of 2008 [10], states, "Early studies of public opinion show that given the ongoing scientific uncertainty about the safety of manufactured nanomaterials in food additives, ingredients and packaging, people do not want to eat nanofoods." program Nine AM with David and Kim, on 18 August 2008). This may or may not be true, but with no reference to the surveys it is hard to know. But the best method for really knowing what the public think is to ask them. The risk of not doing so, or presuming to have a good feel for the public's attitudes, without actually undertaking quality research can be demonstrated, once again, by the GM debate. Public sentiments to new technologies can be pivotal in shaping the direction and pace of scientific activity. ${ }^{6}$

Two studies conducted in the USA and the European Union clearly showed that the perception that a majority of industry and public policy developers had about what the public thought about GM foods and crops did not align with what the public actually thought. ${ }^{7}$

Another problem is undertaking over-simplified polling and holding it up as a valid explanation of complex attitudes. But as much as the general public tends to be attracted to attitudes that mirror their values, so are advocacy groups attracted to polls that mirror their attitudes. It is no surprise then to find industry groups looking for poll results that demonstrate widespread consumer support for nanotechnology products, and NGOs looking for poll results that show consumer concerns about nanotechnology. The reality is that both are a part of the public's attitudes towards nanotechnology, but more in-depth study and

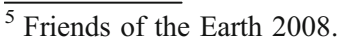

${ }^{6}$ Currall et al. [3].

${ }^{7}$ Public Perceptions of Agricultural Biotechnologies in Europe research project [13].
}

analysis of public attitudes needs to be undertaken to better inform policy and product development.

\section{Studies Done to Date}

Nature nanotechnology listed 12 significant survey studies of public perceptions of nanotechnology in February 2009, with the overall conclusion that while literature on public perceptions is becoming more mature and rigorous, there is still a need to understand public attitudes better, as scientists, policymakers and business will therefore be better positioned to anticipate trends that will dictate how the public might react to new scientific developments or products. ${ }^{8}$

A few of the studies are worth commenting on in a little more detail, for their impact both in what they found or how they were reported. One US study compared the attitudes of the general public with the attitudes of scientists, and interestingly was widely reported as finding that nano-scientists were more concerned about nanotechnology than the general public, ${ }^{9}$ while what the study actually found was that on some issues the scientists were more concerned, and on some the public were more concerned. Across most indicators, the public perceived more benefits than scientists, in relation to topics such as better treatment of diseases, a cleaner environment and a solution of energy problems. However, when risks were addressed the public generally had much higher perception of risks than the scientists, across issues such as loss of privacy, use of the technology by terrorists and loss of jobs.

Also of note, the most divergent perceptions were for job losses, which had almost a $40 \%$ perceived risk by the public and only $5 \%$ perceived risk by the scientists. On two issues, however, the nano-scientists had a higher perception of risk. These were 'more pollution' and 'new health problems' ${ }^{10}$

A study conducted by the Woodrow Wilson International Center for Scholars' Project on Emerging Nanotechnologies, addressed the impact of information on attitudes and found that the more information people obtain about nanotechnology, the more concerned they tend to become. However this had to

\footnotetext{
${ }^{8}$ Currall [2].

${ }^{9}$ Agence France Press [9].

${ }^{10}$ Scheufele et al. [15].
} 
be understood in terms of risk perceptions being largely affect driven, and exposure to information leading to a general polarization along cultural and political lines. ${ }^{11}$

A follow up study to examine the cultural predispositions towards technology and environmental risks found that general unattributed advocacy tended to polarise beliefs, with significant racial and cultural indicators. They study also found that the "gap between people who are generally inclined to credit and those inclined to dismiss claims of environmental risk widens dramatically after exposure to such arguments". The study found that the phenomenon of 'biased assimilation' was a key determinant of attitude, meaning that people tend to credit and dismiss arguments about nanotechnology in patterns that reflect their cultural predispositions towards risk. In practice this means that people assign greater credibility to the opinions of those whose values they share. ${ }^{12}$

\section{The Australian Office of Nanotechnology Study}

The Department of Innovation, Industry, Science and Research's Australian Office of Nanotechnology commissioned studies into public attitudes towards nanotechnology in 2005, 2007 and 2008, detailed in Market Attitude Research Services [7]. ${ }^{13}$ Each study, conducted by an independent market research company, and the methodology employed was random representative sampling through telephone polling of over 1,000 people aged 18 years and over, seeking their responses to a broad range of questions, seeking to understand both attitudes to risks and benefits and different applications. The 2008 study incorporated qualitative comments.

At the simplest level, the findings of the three studies show that public has very high expectations of nanotechnology, concerns are only moderate, while knowledge and awareness are rather low. But to hold these up as the key findings does not do justice to what can be determined by more detailed analysis, which shows these generalisations are often nuanced by attitudes to specific applications. It is crucial to take public opinion polling to this next level of detail to better understand its implications.

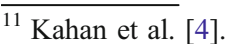

${ }^{12}$ Kahan et al. [5].

${ }^{13}$ Market Attitude Research Services.
}

Interestingly, while discussions of public attitudes towards new technologies need to generally address distinctive demographics differences of attitudes, whether by age, gender or education, breaking down the public into different demographic publics showed very little major differences, so in this instance it is reasonably accurate to refer to the public.

In $2008,86 \%$ of the surveyed population stated they were excited or hopeful about nanotechnology, and believed strongly that it would improve the quality of life in Australia, would have a positive impact on employment and the economy, and would provide great strides in "medical technology" applications in positive ways.

Qualitative comments expressed by people indicated that key areas of science and technology "driving" the average person's interest were towards particular applications that were seen to have clear benefits. These included:

- medical treatment advances_-particularly cervical cancer vaccination;

- science's role in increasing the understanding and potential threat of climate change and potential solutions offered by renewable energy and biofuel technical developments; and

- ongoing advances in computer and internet technology.

\section{Different Attitudes to Different Applications}

As has been stated, while at the simplest level the survey findings could be used to support the claim that the Australian public is strongly supportive of nanotechnologies, when attitudes to different applications are examined, this statement is shown to not always hold up. Currall stated that examining specific applications as opposed to nanotechnology in general is an important direction for further public attitude studies. ${ }^{14}$

For some applications, such as specific medical technologies, support rose over the survey period. For instance, support for using nanotechnology to provide machines that can exist in the blood stream to clear arterial clots and cancer cells, rose from $90 \%$ in 2005 to $94 \%$ in 2008 .

\footnotetext{
${ }^{14}$ Currall [2].
} 
Environmental applications were also highly supported. Using nanotechnology in filers that control pollutants from entering the environment had $96 \%$ support in 2005 and $95 \%$ in 2008, and technology that disassembled and broke down waste and garbage had $91 \%$ support in 2005 and $93 \%$ in 2008 .

However application that had lower support included using nanotechnology in protective suits against chemical or biological weapons (77\% support in 2005 and $74 \%$ support 2008) and stain repellent fabrics (51\% support in 2005 and 2008).

The lowest levels of support, that rated below $50 \%$, were for miniature surveillance devices $(34 \%$ in $2008)$, computers in clothes or goods $(31 \%)$ and changing nutrients in foods (32\%). It is worth noting that attitudes to food showed the only significant change (49\% support in 2005 to $32 \%$ in 2008), and there were clearly different attitudes towards using nanotechnology in food and in food packaging, with the applications of food packing that monitors condition being supported by $73 \%$ of respondents in 2008.

The implications of this is that it is important for nanotechnology applications to align with public values such as public good, rather than more commercial ones.

An issues in understanding public attitude polling on nanotechnology is whether people know what they are responding to, and qualitative comments indicated that outcomes of the application of the technology were a larger driver of attitudes to nanotechnology than attitudes to the technology itself. There is an adage that not knowing what something is does not stop people having strong attitudes towards it, which tends to be supported by the data.

This can be very significant in understanding different response to different polls, and provides insight into attitudes to new technologies may not always be responding to the technology itself, and indicates that public discussions on the technology should focus primarily on its uses rather than how the technology works, to better align with public understandings. This is reinforced by data that while awareness of the term "nanotechnology" (when prompted) was found to be moderate (rising from $51 \%$ in 2005 to $66 \%$ awareness in 2008), specific detailed knowledge of what nanotechnology means was still low (at 8\%). This however is an increase from the 2005 figure of $4 \%$.
Interestingly, US data shows not dissimilar levels of awareness. A 2008 study undertaken for the Woodrow Wilson International Center for Scholars' Project on Emerging Nanotechnologies, found that $49 \%$ had heard nothing at all about nanotechnology (compared to 38\% in Australia) and 26\% had heard just a little (compared to $34 \%$ in Australia). ${ }^{15}$

After testing initial awareness and knowledge of nanotechnology the following definition was provided to respondents in the surveys in an attempt to enable more informed attitudes through providing a common understanding:

"Nanotechnology is science at a very small scale; and refers to a new array of devices and materials whose key parts are less than 10 nanometers, about 10,000 times smaller than the width of a human hair. Its potential is not just about being able to miniaturise things. Working at a scale a million times smaller than a pinhead allows science researchers to "tune" material properties at the atomic level, making them behave in different ways to create new materials and products." 16

There are many different definitions of nanotechnology available, of course, and it may be that a different definition elicited somewhat different response from this point on in the survey.

\section{Risks Versus Benefits}

Many public attitude studies seek to define attitudes as a risk-benefit equation, which can provide a useful indicator of the relativeness of these two factors. Between 2005 and 2008, the public's perception of the benefits outweighing the risks increased (from $39 \%$ to $53 \%$ ) and the perception of risks equalling benefits diminished (from 35\% to 18\%). In 2008 only three per cent perceived there were more risks than benefits, $18 \%$ perceived the risks and benefits might be equal and $26 \%$ were unsure. Again, focussing solely on public perceptions orf risk, or benefit, does not provide the full picture.

Asked to articulate more detail on their perceived risks and benefits of nanotechnology the

\footnotetext{
${ }^{15}$ Peter D Hart Research Associations Inc [11].

${ }^{16}$ OECD [2].
} 
majority (64\%) surveyed in the study expressed no concerns about nanotechnology. Those expressing concerns had mild or positive comments. The mild concerns included:

- nanotechnology regulation and safeguards are not keeping up with the development of nanotechnology;

- because nanotechnology is so new there might be problems for public safety or worker safety; and

- the complexity of nanotechnology makes it difficult to understand.

The only high concern expressed (28\%) related to the use of nanotechnology in food. The implications of this could be further studies to determine the driver of this attitude and whether it was based more on any response to nanotechnology use or modification of foods.

The 2008 US Woodrow Wilson study sought attitudes towards risks and benefits and then provided a definition of nanotechnology, discussing both risks and benefits and retested risk and benefits. The study found that after hearing information there was a 10 point increase in the proportion of respondents who felt that benefits would outweigh risks (from $20 \%$ to $30 \%$ ) and there was a larger $16 \%$ increase from those who thought risks would outweigh benefits $(7 \%$ to $23 \%$ ); a 13 point increase in the proportion saying risks would be equal (25\% to $38 \%$ ) and large drop in those not sure $(48 \%$ to $9 \%) .{ }^{17}$

This supports the assumption that may poll results are based on initial response that can change when the public is more informed. Considering the low levels of awareness of nanotechnology in the public, this also suggests that attitudes are likely to change significantly as people become more informed.

\section{Trust}

Of interest to the public debate is the issue of trust, which can underpin the type of information being sought in a 'crowded market' of competing claims about the risks and benefits of nanotechnology.

The study found that the majority of the Australian community gave high levels of continued trust towards scientists (88\% trust in 2008) to explain any risks associated with nanotechnology.

\footnotetext{
${ }^{17}$ Peter D Hart Research Associations Inc [11].
}

Government agencies and regulators (61\% trust) and non-government organisations (NGO's) (at 64\% trust) were also expected to provide a role of giving information to the Australian community about nanotechnology, and to regulate and monitor the nanotechnology industry. However trust in manufacturers and distributors of consumer products was only $30 \%$ and trust in business leaders was $28 \%$

As to sources of information on nanotechnology, they were dominated by the media. However they were only rated as being trusted to tell of the risks of nanotechnology by $50 \%$. Television, newspapers and radio were cited as reliable sources for information by $80 \%$ of respondents. The internet was cited by $55 \%$ or respondents, and word of mouth by friends, family and colleagues was cited by $9 \%$.

This is also an area for more research, particularly comparing the accuracy of information being obtained from different media.

\section{Qualitative Input}

The 2008 survey sought to probe deeper than the two previous surveys, by allowing for qualitative input from a subset of respondents, and new questioning explored issues where respondents could express opinions about different issues relating to nanotechnology. In relation to the adequacy of safety and testing of consumer products which use nanomaterials or are made using nanotechnology, people expressed views that were categorised as "it is commonsense to test for any potential risks to consumer safety".

Specific comments included:

"I feel OK about this because consumer product testing always seems to be fairly thorough."18

"(Female, aged 40-49 years, Disability Pensioner, Perth - "hopeful about nanotechnology")"

"I have a small amount of concern. But only because it is new technology and the potential exists for unknown factors." 19

"(Male, 60+ years, retired, Townsville-_"hopeful about nanotechnology")"

\footnotetext{
$\overline{{ }^{18} \text { MARS [31]. }}$

${ }^{19}$ MARS [31].
} 
For the impact of nanoparticles entering the environment comments were expressed that "any potential health risks should be assessed, and government agencies and manufacturers should keep the public informed".

Specific comments included:

"I don't have any concerns because a lot of particles enter the environment anyway, and it is only when problems occur you need to worry."20 "(Male, aged 50-59 years, employed full-time, Adelaide- "hopeful about nanotechnology")"

"I am mildly concerned because I am not sure of the situation, except that it sounds possible that the particles could live in the environment and not break down." 21

"(Male, 60+ years, retired, Adelaide- - "hopeful about nanotechnology")"

Addressing nanotechnology use being largely selfregulated by those industries using nanotechnology most comments expressed the view that "governing body regulation is needed" and that "profits should not undercut public safety".

Specific comments included:

"I am not concerned at all because although industry has their own interest at heart, if industry doesn't self regulate then they know the government will step in."22

"(Female, aged 50-59 years, employed part-time, Sydney-"excited about nanotechnology")"

"I am mildly concerned because of financial interests interfering with other interests such as public safety and wellbeing of the environment." 23

"(Male, 30-39 years, employed full-time, Adelaide_-"excited about nanotechnology")"

"I am very concerned because of the motivation and pressure to reduce profits working against self regulation." 24

"(Female, 60+ years, retired, Melbourne-holds neutral view about nanotechnology)"
On the issue of workers and researchers involved with nanotechnology being potentially exposed to nanoparticles comments expressed were related to the view that "any potential health risks need to be addressed by relevant authorities".

Specific comments included:

"Regulations will have safety nets, therefore, I am not concerned - as long as industry does not self regulate." 25

"(Male, aged 40-49 years, employed full-time, Sydney_-"hopeful about nanotechnology")"

"I am only mildly concerned. Health effects always need monitoring to ensure no genetic impacts on offspring and future generations." 26

"(Female, 40-49 years, employed full-time, Brisbane-_"hopeful about nanotechnology")"

Qualitative comments tended to focus on issues of safety and trust to regulate the technology, and demonstrated that when discussing concerns there were clearly large variations that could not be accurately summarised by simple for and against polling. The qualitative polling also provided insights into some of the values that drove attitudes, as well as factors that would mitigate concerns or increase them. However I should also be pointed out that despite many respondents focussing often on concerns, the market research company MARS noted that "at the completion of the above intensive qualitative interviews respondents mostly retained their positive view of nanotechnology or strengthened their positive view about nanotechnology."

The last question put to respondents was:

"Finally, and again thank you for your thoughts, I just want to touch base with you on your final thoughts about nanotechnology based on our discussion today. Overall, what now best describes how you feel about the potential implications of nanotechnology?"

The study found that while $86 \%$ had stated that they were excited or hopeful about nanotechnology during the initial questions of the survey, following the intensive follow-up interview most people

${ }^{20}$ MARS [31].

${ }^{21}$ MARS [31].

${ }^{22}$ MARS [32].

${ }^{23}$ MARS [32].

${ }^{24}$ MARS [32].

$\overline{{ }_{25} \text { MARS [32]. }}$

${ }^{26}$ MARS [32]. 
strengthened positive views held about nanotechnology, with this figure rising to $92 \%$.

Concern and alarm also dropped from $9 \%$ to $6 \%$ after completing the qualitative interviews. This might seem, at first glance, contradictory to the finding that the more people learn about new technologies the more concerned they become, which is reinforced the 2008 Woodrow Wilson study cited earlier, but that may be based on confusing information giving with two-way engagement.

\section{Conclusion}

While the survey conducted for the Australian Office of Nanotechnology provides interesting tracking data on what the public think about nanotechnology, with the top line findings that perceptions of benefits far outweigh risks, one of the key findings of the study is that after having their attitudes sought people tended to have higher support for nanotechnology. It is important that any policy formulation is based on more than topline data, and the study showed that there are concerns relating to specific uses of nanotechnology, especially in foods, and that different applications evoke markedly different attitudes.

Ongoing public attitude studies should therefore continue to seek better quality data, through further engagement with the public, particularly through more two-way engagement, not just in enabling the public to have their say on issues relating to nanotechnology, but in enabling policy and technology developers to have a better sense of understanding of the public's needs and desires, and better match them with nanotechnology developments.

Open Access This article is distributed under the terms of the Creative Commons Attribution Noncommercial License which permits any noncommercial use, distribution, and reproduction in any medium, provided the original author(s) and source are credited.

\section{References}

1. Currall S (2009) New insights into public perception, nature nanotechnology, Volume 4

2. Currall S, King E, Lane N, Madera J, Turner S (2006) What drives public acceptance of nanotechnology, nature nanotechnology, volume 1

3. Inventory of Availability of Nanotechnology Indicators and Statistics OECD Countries, OECD, 2007

4. Kahan D, Slovic P, Braman D, Gastil J, Cohen G (2008) The future of nanotechnology risk perceptions: an experimental investigation of two hypotheses, Harvard Law School Program on Risk Regulation Research Paper No. 08-24, January 31

5. Kahan D, Slovic P, Braman D, Gastil J, Cohen G, Kysar D (2008) Biased assimilation, polarization, and cultural credibility: an experimental study of nanotechnology risk perception, PEN Brief No 3

6. Kahan D, Slovic P, Braman D, Gastil J, Choen G (2007) Affect, values, and nanotechnology risk perceptions: an experimental investigation, cultural cognition project working paper 22

7. Market Attitude Research Services (2008) Australian community attitudes held about nanotechnology-trends 2005-2008, Australian Office of Nanotechnology report

8. Nanotechnology: A Global Strategic Business Report (2008) Global Industry Analysts, Inc

9. On nanotechnology, experts see more risks than public (2007) Agence France Press, Nov 25

10. Out of the Laboratory and on to our Plates: Nanotechnology in Food and Agriculture (2008) Friends of the Earth

11. Peter D Hart Research Associations Inc (2008) Awareness of and attitudes towards nanotechnology and synthetic biology, Woodrow Wilson International Center for Scholars' Project on Emerging Nanotechnologies

12. Project on Emerging Nanotechnologies Consumer Product Inventory at: http://www.nanotechproject.org/inventories/ consumer/

13. Public Perceptions of Agricultural Biotechnologies in Europe research project (2004)

14. Rejeski D, Lekas D (2008) Nanotechnology field observations: scouting the new industrial west. J Clean Prod 16:1014-1017

15. Scheufele D, Corley DS, Shih T, Hillback E, Guston D (2007) Scientists worry about some risks more than the public. Nature Nanotechnology 2:732-734 